\title{
Schistosoma Japonicum Infection
}

National Cancer Institute

\section{Source}

National Cancer Institute. Schistosoma Japonicum Infection. NCI Thesaurus. Code C35001.

An infection that is caused by Schistosoma japonicum. 